\title{
Effect of amlodipine on ventricular hypertrophy in hypertension patients: a systematic review and meta-analysis
}

\author{
Yi Gao ${ }^{1,2}$, Di Zhou ${ }^{3}$, Ping Yang ${ }^{1,2}$ \\ ${ }^{1}$ Department of Cardiology, China-Japan Union Hospital of Jilin University, Changchun, China; ${ }^{2}$ Jilin Provincial International Collaboration \\ Research Center for Precision Medicine, Changchun, China; ${ }^{3}$ Department of Hematology and Oncology, China-Japan Union Hospital of Jilin \\ University, Changchun, China \\ Contributions: (I) Conception and design: Y Gao, P Yang; (II) Administrative support: P Yang; (III) Provision of study materials or patients: Y Gao, D \\ Zhou; (IV) Collection and assembly of data: Y Gao, D Zhou; (V) Data analysis and interpretation: D Zhou; (VI) Manuscript writing: All authors; (VII) \\ Final approval of manuscript: All authors. \\ Correspondence to: Dr. Ping Yang. Department of Cardiology, China-Japan Union Hospital of Jilin University \& Jilin Provincial International \\ Collaboration Research Center for Precision Medicine, No.126, Xiantai Street, Changchun 130033, China. Email: pyang@jlu.edu.cn.
}

Background: Left ventricular (LV) hypertrophy predicts worse cardiac outcomes. Blood pressure lowering is associated with the reduction of LV hypertrophy. This study evaluated the effect of a calcium channel blocker, amlodipine, on LV hypertrophy in patients with hypertension.

Methods: Studies were identified by conducting a literature survey in electronic databases, and study selection was carried out according to precise eligibility criteria. Meta-analyses of mean change between the follow-up and baseline values of systolic/diastolic blood pressure (SBP/DBP) and LV hypertrophy indices were performed. Meta-regression analyses were performed to examine the factors affecting changes in these indices.

Results: Twenty-three studies [involving 737 patients; age 56.4 years, 95\% confidence interval (CI): 53.5-59.2; females 34\%, 95\% CI: 25-44\%; body mass index $26.4 \mathrm{~kg} / \mathrm{m}^{2}$, 95\% CI: 24.6-28.1] were included. Amlodipine treatment led to a significant reduction in SBP $(-24.9 \mathrm{mmHg}$; $95 \% \mathrm{CI}$ : -28.3 to -21.6 ; $\mathrm{P}<0.0001)$ and DBP $(-14.8 ; 95 \%$ CI: -16.4 to -13.3 ; $<<0.0001)$, without affecting the heart rate. Amlodipine treatment also significantly reduced the LV mass index. The mean difference (MD) between the follow-up and baseline LV mass index was -12.9 ; 95\% CI: -15.4 to $-10.4(\mathrm{P}<0.001)$. This decrease in LV mass index was positively associated with the follow-up duration [meta-regression coefficient (MC): 0.392; $95 \%$ CI: 0.050-0.733; P=0.026] and baseline LV mass index (MC: 0.139; 95\% CI: 0.007-0.271; P=0.040). Amlodipine treatment significantly reduced the $\mathrm{LV}$ posterior wall thickness, which was also positively associated with the follow-up duration. There was no significant decrease in the LV end-diastolic diameter following amlodipine treatment.

Discussion: Amlodipine treatment in patients with hypertension significantly reduced the LV mass index and LV posterior wall thickness, without notably affecting the LV end-diastolic diameter. Since many of the included studies were non-randomized, open-label, or lacking appropriate comparability, we therefore performed pooled analyses of the changes from baseline, and a comparative account could not be carried out.

Keywords: Hypertension; ventricular hypertrophy; myocardial; amlodipine

Submitted Aug 12, 2021. Accepted for publication Oct 19, 2021.

doi: 10.21037/apm-21-2455

View this article at: https://dx.doi.org/10.21037/apm-21-2455 


\section{Introduction}

Left ventricular (LV) hypertrophy is an echocardiographic index that indicates the presence of high LV mass (1). An $\mathrm{LV}$ mass index value equal to or above the $95^{\text {th }}$ percentile is considered LV hypertrophy (2), and an LV mass index of over $115 \mathrm{~g} / \mathrm{m}^{2}$ in men and $95 \mathrm{~g} / \mathrm{m}^{2}$ in women is used diagnose LV hypertrophy (3). LV hypertrophy develops due to the increased size of cardiomyocytes, which affects the structure and function of the LV. LV hypertrophy can be either a physiological adaptation to strenuous physical exercise that eventually regresses upon the low activity, or it can be a pathological manifestation of hemodynamic overload or gene expression leading to LV dysfunction, which can cause heart failure (4). The prevalence of LV hypertrophy in patients with hypertension varies according to the LV hypertrophy threshold cutoff (5) and ranges between $36 \%$ and $46 \%$ in patients with hypertension (6). Eccentric LV hypertrophy has been found to be more prevalent than concentric LV hypertrophy (6).

$\mathrm{LV}$ hypertrophy is an independent predictor of fatal or non-fatal cardiovascular disease (CVD) events, especially coronary heart disease, congestive heart failure, myocardial infarction, heart failure, stroke, or mortality. Meanwhile, the reduction of $\mathrm{LV}$ hypertrophy indices is associated with a reduced risk of subsequent CVD and mortality (7-9). In hypertension patients without LV hypertrophy at baseline, blood pressure lowering has been found to be associated with a $46 \%$ risk reduction of developing LV hypertrophy, whereas in patients with LV hypertrophy at baseline, intensive blood pressure treatment has been shown to make the regression of LV hypertrophy 66\% more likely (10).

LV hypertrophy develops as a pathophysiological adaptation against the increased afterload in patients with hypertension (11). LV hypertrophy is a strong predictor of CVD complications in patients with essential hypertension (1). Higher hemodynamic load in hypertensive patients leads to increased LV mass, which causes eccentric or concentric LV hypertrophy or geometric remodeling. Compared with eccentric hypertrophy, the presence of concentric LV hypertrophy in hypertensive patients poses the highest risk of CVD events and mortality (12). Besides hypertension, neurohormonal agents, angiotensin II, norepinephrine, aldosterone, insulin, and other growth factors play roles in the development and promotion of LV hypertrophy (13).

Calcium channel blockers constitute an important class of antihypertensive drugs which are found efficacious in reversing LV hypertrophy (14). Dihydropyridine calcium channel blockers are reported to reduce risk of heart failure, stroke, and mortality (15). Amlodipine is a long-acting dihydropyridine calcium channel blocker, which has been used as an effective antihypertensive for over three decades. Whereas the antihypertensive effects of amlodipine are well-reviewed (16-18), there is no systematic review or meta-analysis to analyze the effects of amlodipine on LV hypertrophy. Several studies have reported the outcomes of amlodipine treatment in hypertensive patients, many of which have also evaluated its effects on LV hypertrophy indices. However, the outcomes vary across these studies. The present study aimed to evaluate the effect of amlodipine on LV hypertrophy indices in patients with hypertension by conducting a systematic review of relevant studies and performing meta-analyses of important indices to quantitatively estimate the changes observed after treatment. We present the following article in accordance with the PRISMA reporting checklist (available at https:// dx.doi.org/10.21037/apm-21-2455).

\section{Methods}

\section{Eligibility criteria}

The inclusion criteria were as follows: (I) studies that evaluated the efficacy of amlodipine in patients with hypertension; (II) studies that reported outcomes related to the evaluation of ventricular hypertrophy, including LV mass, $L V$ mass index, $L V$ posterior wall thickness, relative wall thickness, LV end-diastolic diameter, and peak early diastolic filling velocity (E) to peak filling velocity at atrial contraction (A) ratio (E/A ratio); and (III) studies that reported the values of endpoints at baseline and at latest follow-up or the changes from baseline in one or more of the aforementioned indices. However, studies were excluded if they evaluated the efficacy of amlodipine in combination with other drugs, or reported the outcomes as congress abstracts.

\section{Literature search}

The literature survey was conducted in electronic databases (Google Scholar, Ovid, PubMed, and Science Direct) using the most relevant keywords, including amlodipine, calcium channel antagonist, calcium blocker, antihypertensive, hypertension patients, ventricular hypertrophy, myocardial hypertrophy, LV mass, and echocardiography. The literature search encompassed research articles published from the date of inception of the database till June 2021. 
Additionally, the bibliographic sections of important research and review articles were also screened. The literature search was restricted to research articles published in the English language.

\section{Statistical analyses}

Demographic and anthropometric data, clinical and pathological data, echocardiographic and Doppler indices, study design and analytical details, outcome measures, and outcomes were extracted from the research articles of selected studies and tabulated on software datasheets. Quality assessment of the included randomized studies was performed with the Cochrane Risk of Bias Assessment Tool for Randomized Controlled Trials (Collaborative Review Group, CRG), while the Newcastle-Ottawa Scale for the Assessment of Quality of Cohort Studies was used to assess the quality of non-randomized studies. Publication bias assessment was performed with Egger's precision test and Begg's rank correlation test.

To measure the changes in outcome endpoints, metaanalyses of the mean difference (MD) between the followup and baseline values were performed. For this purpose, the mean changes and variance were calculated if these were not reported by the individual studies (19). These mean changes and their variances were then used in metaanalyses using the DerSimonian-Liard pooled method to achieve overall and subgroup estimates. Sensitivity analyses were performed where feasible. For the present study, the endpoints of interest were the mean changes in systolic/diastolic blood pressure (SBP/DBP), heart rate (HR), LV mass index, LV posterior wall thickness, LV enddiastolic diameter, and the E/A ratio. The $\mathrm{I}^{2}$ index was used to estimate inconsistencies in the outcomes between studies.

Meta-regression analyses were performed using the restricted maximum likelihood method to seek relationships between the changes in $\mathrm{LV}$ mass index, $\mathrm{LV}$ posterior wall thickness, and LV end-diastolic diameter and explanatory variables including age, follow-up duration, and baseline values of $L V$ mass index, $L V$ posterior wall thickness, $L V$ end-diastolic diameter, and the E/A ratio. Meta-analyses and meta-regression were performed using Stata software (version 12; Stata Corporation, College Station, Texas, USA).

\section{Results}

A total of 23 studies $(11,13,20-40)$ were included (Figure 1), and the data of 737 patients with hypertension were used in this meta-analysis. Important characteristics of the included studies are presented in Table S1. The age of patients in these studies was 56.4 years [ $95 \%$ confidence interval (CI): 53.5-59.2] (range, $46 \pm 6$ to $67 \pm 4$ ). The proportion of females in this population was $34 \%$ (95\% CI: $25-44 \%$ ). The body mass index of patients in these studies ranged from $23 \pm 4$ to $31 \pm 7$, with a weighted average of $26.4 \mathrm{~kg} / \mathrm{m}^{2}$ (95\% CI: 24.6-28.1).

There was no significant publication bias according to Begg's (Adjusted Kendall score $=-10 \pm 14.6 ; \mathrm{P}=0.493$ ) or Egger's (bias coefficient -0.937 ; $95 \%$ CI: -2.36 to 0.49 ; $\mathrm{P}=0.173$ ) tests (Figure S1). The quality of the randomized studies varied from moderate to high. A lack of blinding of personnel, participants, or outcome assessment was observed in some randomized studies (Table S2). In non-randomized prospective or retrospective studies, comparability was the main constraint (Table S3).

Nineteen studies reported the changes in SBP and DBP after amlodipine treatment. Amlodipine treatment led to a significant reduction in SBP $(-24.9 \mathrm{mmHg}$; 95\% CI: -28.3 to $\left.-21.6 ; \mathrm{I}^{2}=95 \% ; \mathrm{P}<0.0001\right)$ and DBP $(-14.8 \mathrm{mmHg} ; 95 \%$ CI: -16.4 to $\left.-13.3 ; \mathrm{P}<0.0001 \mathrm{I}^{2}=90 \%\right)$ overall. The change in blood pressure was similar at 3 months, 6 months, and $>1$ year of follow-up (Table 1). There was no significant change in the HR during amlodipine treatment at any follow-up duration point (Table 1).

Eighteen studies reported the changes in LV mass index. After amlodipine treatment, the LV mass index decreased during follow-up (Table 2; Figure 2). The overall change in the $\mathrm{LV}$ mass index was statistically significant $(-12.9$; $95 \%$ CI: -15.4 to $-10.4 ; \mathrm{P}<0.001)$. Outcomes of sensitivity analyses were in agreement with the overall outcomes. A decrease in the LV mass index was positively associated with the follow-up duration (meta-regression coefficient, MC: 0.392; 95\% CI: $0.050-0.733 ; \mathrm{P}=0.026)$ as well as with the baseline LV mass index (MC: 0.139; 95\% CI: 0.007-0.271; $\mathrm{P}=0.040$ ) (Figure S2A,S2B).

Nine studies reported the changes in LV posterior wall thickness. Amlodipine treatment also led to a significant reduction in the $L V$ posterior wall thickness (Figure 3). In the subgroup analysis, the change in $\mathrm{LV}$ posterior wall thickness increased further from 3 and 6 months to 1-3 years of follow-up (Table 2). Also, the meta-regression analysis showed that the decrease in $L V$ posterior wall thickness was positively related to the follow-up duration (MC: 0.042; 95\% CI: 0.007-0.076; $\mathrm{P}=0.021$; Figure S3).

Eleven studies reported the changes in LV end-diastolic 


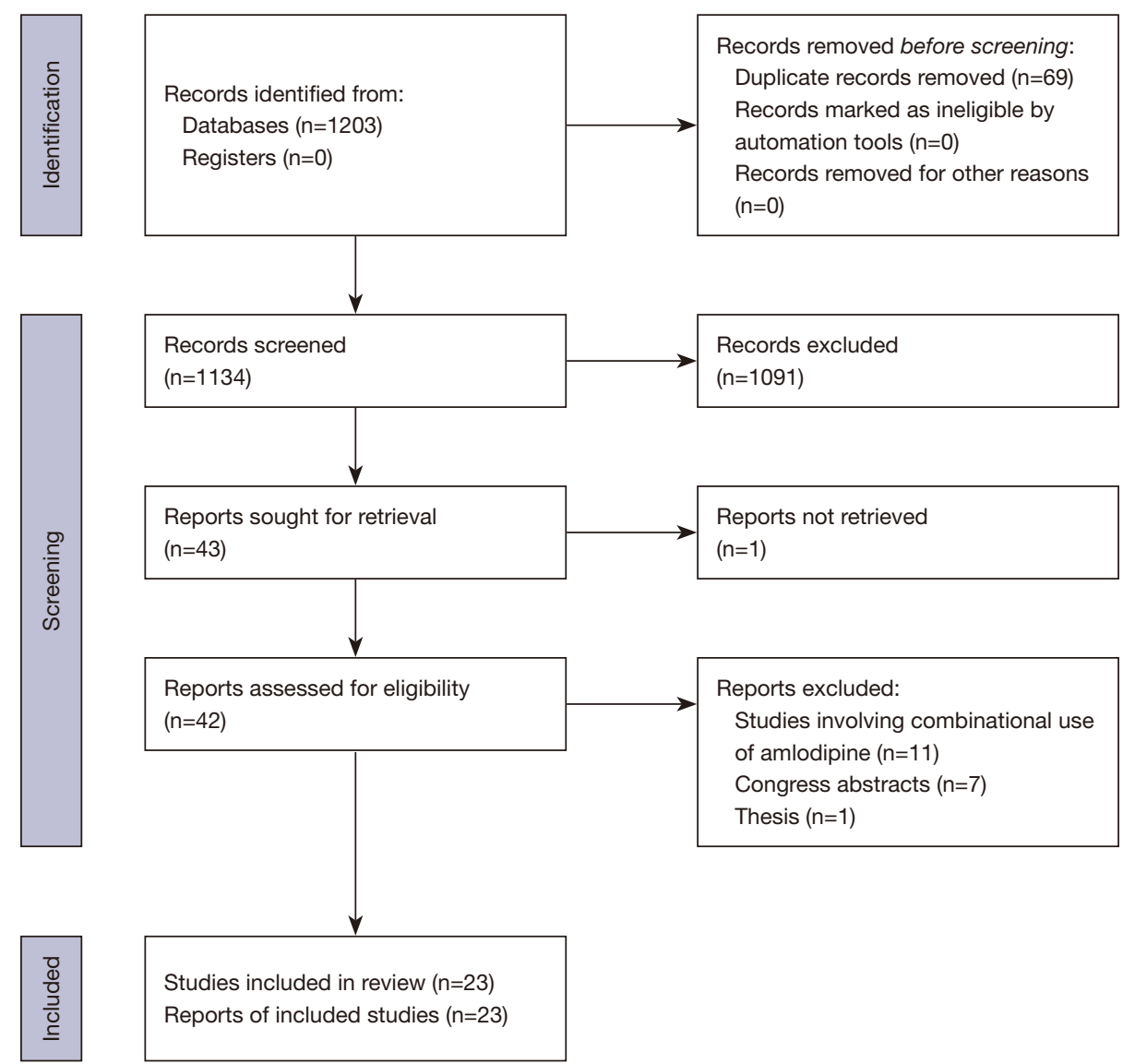

Figure $1 \mathrm{~A}$ flowchart of the study screening and selection process.

Table 1 Changes in blood pressure and heart rate at different time points during amlodipine treatment

\begin{tabular}{|c|c|c|c|}
\hline Follow-up & Systolic blood pressure $(\mathrm{mmHg})$ & Diastolic blood pressure $(\mathrm{mmHg})$ & Heart rate (beats per minute) \\
\hline 6 months & $\begin{array}{c}-24.8(-30.1 \text { to }-19.5) \\
I^{2}=96 \% ; P<0.000\end{array}$ & $\begin{array}{c}-13.9(-16.0 \text { to }-11.8) \\
I^{2}=90 \% ; P<0.0001\end{array}$ & $\begin{array}{c}-0.79(-2.16 \text { to } 0.57) \\
I^{2}=21 \% ; P=0.255\end{array}$ \\
\hline $1-3$ years & $\begin{array}{c}-27.5(-32.8 \text { to }-22.3) \\
I^{2}=88 \% ; P<0.0001\end{array}$ & $\begin{array}{c}-13.6(-16.3 \text { to }-10.9) \\
I^{2}=80 \% ; P<0.0001\end{array}$ & $\begin{array}{c}-3.43(-7.22 \text { to } 0.37) \\
I^{2}=0 \% ; P=0.077\end{array}$ \\
\hline
\end{tabular}

diameter. There was no significant decrease in the LV enddiastolic diameter after amlodipine treatment overall. In the subgroup analysis, a reduction in the $\mathrm{LV}$ end-diastolic diameter after amlodipine treatment was only observed in the 1-3 months follow-up subgroup (Table 2; Figure S4). The decrease in LV end-diastolic diameter was inversely associated with the duration of follow-up $(-0.251$; $95 \% \mathrm{CI}$ : -0.402 to $-0.100 ; \mathrm{P}=0.003$; Figure $\mathrm{S} 5$ ).

Furthermore, there was a trend towards an increase in the E/A ratio with the follow-up in each study, although this relationship was not statistically significant (MC: 0.072; 95\% CI: -0.017 to $0.161 ; \mathrm{P}=0.106$; Figure 4). 
Table 2 Changes in LV hypertrophy indices at different time points during amlodipine treatment

\begin{tabular}{lccc}
\hline Follow-up & LV mass index $\left(\mathrm{g} / \mathrm{m}^{2}\right)$ & LV posterior wall thickness $(\mathrm{mm})$ & LV end-diastolic diameter (mm) \\
\hline Overall (1-36 months) & $-12.9(-15.4$ to -10.4$) ;$ & $-0.82(-1.00$ to -0.63$) ;$ & $-0.59(-1.42$ to 0.24$) ;$ \\
& $I^{2}=96 \% ; P<0.0001$ & $I^{2}=66 \% ; P<0.001$ & $-1.24(-2.10$ to 0.40$)$ \\
1-3 months & $-9.42(-13.1$ to -5.78$) ; I^{2}=95 \% ;$ & $-0.57(-0.71$ to -0.44$) ;$ & $I^{2}=63 \% ; P=0.004$ \\
& $P<0.0001$ & $I^{2}=15 \% ; P<0.001$ & $-0.48(-1.05$ to 0.10$) ;$ \\
6 months & $-11.4(-13.9$ to -9.0$) ; I^{2}=75 \% ;$ & $-1.03(-1.23$ to -0.83$) ;$ & $I^{2}=4 \% ; P=0.104$ \\
& $P<0.0001$ & $I^{2}=0 \% ; P<0.001$ & $0.68(-2.39$ to 3.76$) ;$ \\
$1-3$ years & $-17.7(-22.9$ to -12.6$) ;$ & $-1.09(-1.33$ to -0.84$) ;$ & $I^{2}=87 \% ; P=0.819$
\end{tabular}

\section{Discussion}

This meta-analysis found that amlodipine treatment led to significant reductions in ventricular hypertrophy indices. The LV mass index decreased more in individuals with higher baseline LV mass index. The decrease in LV mass index and LV posterior wall thickness was positively associated with the follow-up duration, but the decrease in $\mathrm{LV}$ end-diastolic diameter was inversely associated with follow-up. These changes were associated with significant reductions in SBP and DBP, without a notable effect on HR. The E/A ratio increased non-significantly throughout the follow-up period.

Calcium channel blockers, in general, have been found to be associated with a considerable reduction in LV hypertrophy. In a meta-analysis of 52 randomized comparative studies with at least 6-months follow-up, Salvetti et al. found a $12.3 \%$ decrease in the $\mathrm{LV}$ mass index with calcium channel blockers, which was comparable to the $12.5 \%$ for angiotensin receptor blockers and $11.1 \%$ for angiotensin-converting enzyme inhibitors. They found a correlation coefficient of $0.44(\mathrm{P}<0.001)$ between the change in LV mass and SBP (14). In the present study, we observed approximately $13 \%$ reduction in the LV mass index overall, and the correlation coefficients between the change in SBP/DBP and the change in $\mathrm{LV}$ mass index of $0.26(\mathrm{P}=0.247) / 0.32(\mathrm{P}=0.143)$. We also found that the correlation between the changes in the $\mathrm{LV}$ mass index and $\mathrm{LV}$ posterior wall thickness was $0.35(\mathrm{P}=0.239)$, while the correlation between the changes in the $\mathrm{LV}$ mass index and $\mathrm{LV}$ end-diastolic diameter was $0.04(\mathrm{P}=0.9)$. Significant reductions in $\mathrm{LV}$ mass index are also observed with other calcium channel blockers including nifedipine, felodipine, and manidipine (41-43).

Combinational use of amlodipine with other related drugs exhibits better efficacy in reversing LV hypertrophy. Amlodipine in combination with benazepril (an angiotensin converting enzyme inhibitor) has been found to decrease $\mathrm{LV}$ mass index by $30 \pm 26 \mathrm{~g} / \mathrm{m}^{2}$ in comparison with $14 \pm 22 \mathrm{~g} / \mathrm{m}^{2}$ by amlodipine monotherapy (44). In patients with hypertension and hypercholesterolemia, amlodipine in combination with atorvastatin reduced left ventricular mass index (LVMI) significantly more than amlodipine monotherapy (45). Utilizing the chronotherapeutic approach, Ikeda et al. treated hypertension patients with bed-time alpha-adrenergic receptor antagonist, doxazosin, as an add-on treatment to amlodipine and found that this intervention significantly reduced morning blood pressure and LV hypertrophy. Authors suggested that this combination can be useful for patients with metabolic syndrome or insulin resistance (46). Factors other than drug class or dosage can also affect the combinational therapies e.g., a polytherapy with amlodipine, perindopril and indapamide was more effective in reversing $\mathrm{LV}$ hypertrophy as triple fixed dose combination than as triple free combination (47).

The LV hemodynamic workload is affected by blood pressure levels. Among the hemodynamic and nonhemodynamic factors involved in the pathogenesis of $\mathrm{LV}$ hypertrophy, blood pressure is a major factor (48). After finding no significant change in $\mathrm{LV}$ end-diastolic diameter with amlodipine treatment, Cerasola et al. suggested that a decrease in the $\mathrm{LV}$ mass index could be due to the reduction in $L V$ posterior wall thickness. On the other hand, since amlodipine treatment significantly reduced both SBP and DBP; therefore, a decrease in LV mass could be attributed to hemodynamic modifications (11). Rosendorff et al., who stabilized blood pressure before echocardiographic measurements in hypertensive patients treated with amlodipine or losartan, found that the LV 


\begin{tabular}{|c|c|c|}
\hline $\begin{array}{l}\text { Study } \\
\text { ID }\end{array}$ & $\begin{array}{l}\text { Change from } \\
\text { baseline }(95 \% \mathrm{Cl})\end{array}$ & $\begin{array}{l}\% \\
\text { Weight }\end{array}$ \\
\hline Change by $1-3$ months & & \\
\hline Adalet 1995 & $-18.00(-30.70,-5.30)$ & 2.32 \\
\hline Cerasola 1997 & $-3.00(-6.32,0.32)$ & 5.24 \\
\hline Fak 1996 & $-23.00(-37.20,-8.80)$ & 2.02 \\
\hline Gaudio 2003 & $-16.70(-25.48,-7.92)$ & 3.38 \\
\hline Kloner 1995 & $-20.00(-22.58,-17.42)$ & 5.44 \\
\hline Leenen 1996 & $-6.00(-6.71,-5.29)$ & 5.74 \\
\hline Martina 1999 & $-10.00(-23.60,3.60)$ & 2.13 \\
\hline Motoki 2014 & $-7.00(-31.30,17.30)$ & 0.90 \\
\hline Sarkar 2017 & $-3.00(-3.84,-2.16)$ & 5.73 \\
\hline Takami 2003 & $-3.00(-8.40,2.40)$ & 4.55 \\
\hline Subtotal $(\mathrm{I}$-squared $=94.9 \%, \mathrm{P}=0.000)$ & $-9.41(-13.05,-5.78)$ & 37.45 \\
\hline . & & \\
\hline Change by 6 months & & \\
\hline Adalet 1996 & $-24.00(-36.40,-11.60)$ & 2.39 \\
\hline Bilge 2005 & $-17.00(-34.50,0.50)$ & 1.51 \\
\hline Cerasola 2012 & $-12.00(-15.00,-9.00)$ & 5.33 \\
\hline Fak 1996 & $-27.00(-41.00,-13.00)$ & 2.06 \\
\hline Gaudio 2003 & $-19.00(-27.80,-10.20)$ & 3.37 \\
\hline Leenen 1996 & $-10.00(-10.71,-9.29)$ & 5.74 \\
\hline Motoki 2014 & $-17.00(-39.30,5.30)$ & 1.03 \\
\hline Rutuparana 2017 & $-12.30(-13.87,-10.73)$ & 5.64 \\
\hline Takami 2003 & $-9.00(-15.50,-2.50)$ & 4.15 \\
\hline Yasunari 2004 & $-3.00(-7.00,1.00)$ & 5.03 \\
\hline Subtotal $(\mathrm{I}$-squared $=74.9 \%, \mathrm{P}=0.000)$ & $-11.41(-13.86,-8.95)$ & 36.26 \\
\hline$\cdot$ & & \\
\hline Change by $1-3$ years & & \\
\hline Beltman $19981 \mathrm{yr}$ & $-11.00(-16.00,-6.00)$ & 4.69 \\
\hline Fogari $20121 \mathrm{yr}$ & $-13.40(-19.67,-7.13)$ & 4.24 \\
\hline Matsuno $20113 \mathrm{yr}$ & $-16.50(-21.46,-11.54)$ & 4.71 \\
\hline Motoki $20141 \mathrm{yr}$ & $-16.00(-39.60,7.60)$ & 0.94 \\
\hline Terpstra $20011 \mathrm{yr}$ & $-18.40(-21.73,-15.07)$ & 5.24 \\
\hline Terpstra20012 yr & $-25.70(-28.44,-22.96)$ & 5.40 \\
\hline Yamamoto $20111.5 \mathrm{yr}$ & $-28.00(-49.70,-6.30)$ & 1.08 \\
\hline Subtotal $(\mathrm{I}$-squared $=83.6 \%, \mathrm{P}=0.000)$ & $-17.74(-22.92,-12.56)$ & 26.29 \\
\hline & & \\
\hline Overall $(\mathrm{I}$-squared $=95.5 \%, \mathrm{P}=0.000)$ & $-12.92(-15.42,-10.41)$ & 100.00 \\
\hline \multicolumn{3}{|l|}{ NOTE: Weights are from random effects analysis } \\
\hline & & \\
\hline
\end{tabular}

Figure 2 A forest graph showing the outcomes of the meta-analysis of changes from baseline in the left ventricular mass index.

hypertrophy-decreasing effects of these drugs were largely pressor dependent (34). However, the study of Fogari et al. showed that amlodipine and losartan affect the LV mass differently, while reducing blood pressure similarly. In their study, losartan was more effective than amlodipine at reducing the $L V$ mass and $L V$ posterior wall thickness (24). Amlodipine treatment has also been found to be associated with reduction in arterial stiffness which appear to happen via both blood pressure dependent and independent mechanisms (49).
We found that the reduction in $\mathrm{LV}$ mass index was positively associated with the follow-up duration and baseline LV mass index. A previous meta-analysis that evaluated the efficacy of several antihypertensive drug classes in reducing LV hypertrophy reported that the percentage change in the LV mass index was positively associated with the follow-up duration and baseline LV mass index (50). These data suggest that more changes occur in patients with a high baseline LV mass index and that therapy can provide long-term benefits. However, consideration of 


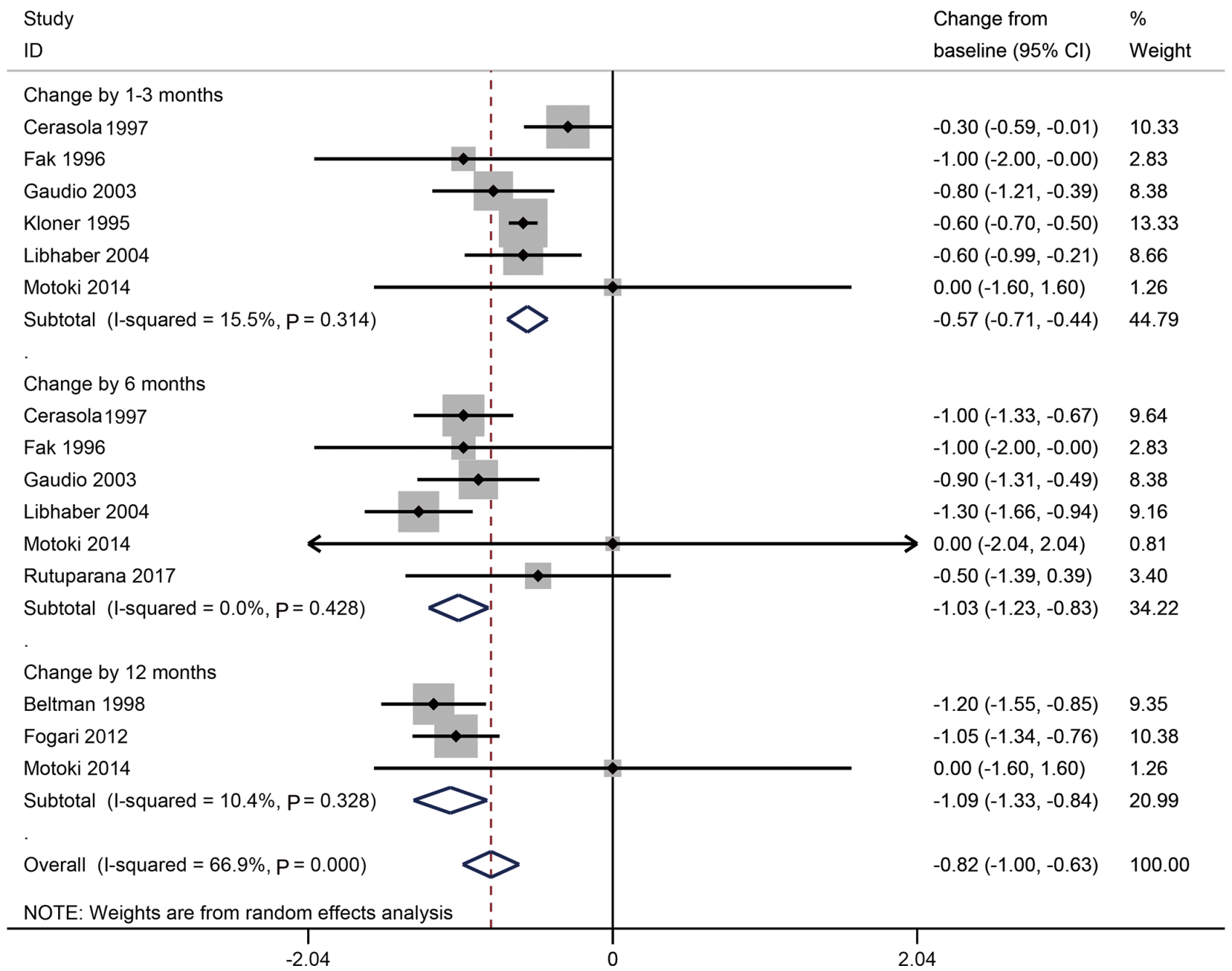

Figure 3 A forest graph showing the outcomes of the meta-analysis of changes from baseline in the left ventricular posterior wall thickness.

an adequate follow-up duration will be necessary to evaluate this observation. In the present study, the average follow-up duration was 10 months (range, $1-36$ months).

Subclinical organ damage is initiated when chronic hypertension begins causing cardiac remodeling. The development of LV hypertrophy involving the growth of myocytes, increased oxidative stress, increased action of vasoactive substances, and fibrosis leads to several cardiac pathologies (51). LV mass is associated with increased myocardial oxygen consumption, reduced coronary blood flow reserve, increased atherosclerotic lesions, and arrhythmogenesis (1). It is thought that amlodipine may regress the $L V$ mass by decreasing both the afterload and intracellular calcium ions, which can retard protein synthesis (33). Cardiomyopathic damage is associated with release of biochemical markers. A strong positive correlation has been found between serum high sensitivity cardiac troponin $\mathrm{T}(\mathrm{hs}-\mathrm{c} T \mathrm{TnT})$ and LVMI $(\mathrm{r}=0.608 ; \mathrm{P}<0.001)$ in patients with end-stage renal disease under dialysis (52). In a cohort of patients with chronic kidney disease without heart failure, high hs-cTnT levels were predictive of LV hypertrophy (53). In individuals without CVD from general population, hs-cTnT levels were found to be positively associated with $\mathrm{LV}$ mass index so that $\mathrm{LV}$ mass, $\mathrm{LV}$ mass index, and LV hypertrophy values increased with increasing quintiles of hs-cTnT levels. Moreover, hs-cTnT levels were inversely associated with diastolic function irrespective of $\mathrm{LV}$ mass which showed that hs-cTnT may be used as an early marker of heart disease involving diastolic dysfunction (54).

Some limitations of the present study are important 


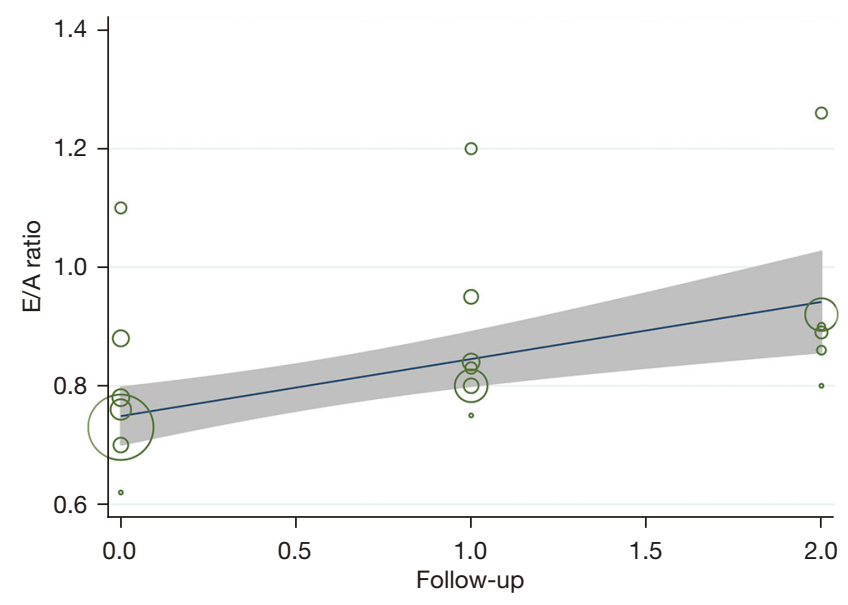

Figure 4 A meta-regression scatterplot showing a trend towards an increased E/A ratio at the middle and end points of followup observed by individual studies. E/A, peak early diastolic filling velocity to peak filling velocity at atrial contraction ratio.

to consider while interpreting the outcomes. Our metaanalyses outcomes were associated with high $\mathrm{I}^{2}$ values, which reflect high levels of inconsistency in outcomes between included studies. The included studies in this meta-analysis varied in design, ranging from retrospective to prospective and from open-label to double-blind randomized controlled trials. Different etiologies and severity of hypertension in these studies could have also impacted the outcomes. Such factors might have contributed to the high $\mathrm{I}^{2}$ values. Since many of the included studies were non-randomized, openlabel, or lacking appropriate comparability, we therefore performed pooled analyses of the changes from baseline, and a comparative account could not be carried out.

\section{Conclusions}

Amlodipine treatment in patients with hypertension is associated with significant reductions in LV hypertrophy and blood pressure without affecting HR. During an average follow-up of approximately 10 months, reduction in the LV mass index increased with increasing duration of follow. These results show that amlodipine therapy can significantly reduce blood pressure and LV hypertrophy in the long term, especially in patients with higher LV hypertrophy indices at baseline.

\section{Acknowledgments}

Funding: None.

\section{Footnote}

Reporting Checklist: The authors have completed the PRISMA reporting checklist. Available at https://dx.doi. org/10.21037/apm-21-2455

Conflicts of Interest: All authors have completed the ICMJE uniform disclosure form (available at https://dx.doi. org/10.21037/apm-21-2455). The authors have no conflicts of interest to declare.

Ethical Statement: The authors are accountable for all aspects of the work in ensuring that questions related to the accuracy or integrity of any part of the work are appropriately investigated and resolved.

Open Access Statement: This is an Open Access article distributed in accordance with the Creative Commons Attribution-NonCommercial-NoDerivs 4.0 International License (CC BY-NC-ND 4.0), which permits the noncommercial replication and distribution of the article with the strict proviso that no changes or edits are made and the original work is properly cited (including links to both the formal publication through the relevant DOI and the license). See: https://creativecommons.org/licenses/by-nc-nd/4.0/.

\section{References}

1. Schillaci G, Verdecchia P, Porcellati C, et al. Continuous relation between left ventricular mass and cardiovascular risk in essential hypertension. Hypertension 2000;35:580-6.

2. Korner PI, Jennings GL. Assessment of prevalence of left ventricular hypertrophy in hypertension. J Hypertens 1998;16:715-23.

3. Cuspidi C, Esposito A, Negri F, et al. Studies on left ventricular hypertrophy regression in arterial hypertension: a clear message for the clinician? Am J Hypertens 2008;21:458-63.

4. Lazzeroni D, Rimoldi O, Camici PG. From Left Ventricular Hypertrophy to Dysfunction and Failure. Circ J 2016;80:555-64.

5. Conrady AO, Rudomanov OG, Zaharov DV, et al. Prevalence and determinants of left ventricular hypertrophy and remodelling patterns in hypertensive patients: the St. Petersburg study. Blood Press 2004;13:101-9.

6. Cuspidi C, Sala C, Negri F, et al. Prevalence of leftventricular hypertrophy in hypertension: an updated review of echocardiographic studies. J Hum Hypertens 
2012;26:343-9.

7. Vasan RS, Larson MG, Levy D, et al. Distribution and categorization of echocardiographic measurements in relation to reference limits: the Framingham Heart Study: formulation of a height- and sex-specific classification and its prospective validation. Circulation 1997;96:1863-73.

8. Krauser DG, Devereux RB. Ventricular hypertrophy and hypertension: prognostic elements and implications for management. Herz 2006;31:305-16.

9. Cuspidi C, Facchetti R, Bombelli M, et al. Differential value of left ventricular mass index and wall thickness in predicting cardiovascular prognosis: data from the PAMELA population. Am J Hypertens 2014;27:1079-86.

10. Soliman EZ, Ambrosius WT, Cushman WC, et al. Effect of Intensive Blood Pressure Lowering on Left Ventricular Hypertrophy in Patients With Hypertension: SPRINT (Systolic Blood Pressure Intervention Trial). Circulation 2017;136:440-50.

11. Cerasola G, Nardi E, Cottone S, et al. Influence of the calcium antagonist amlodipine on left ventricular mass and function in patients with essential hypertension. Clin Drug Invest 1997;13:17-21.

12. Verma A, Meris A, Skali H, et al. Prognostic implications of left ventricular mass and geometry following myocardial infarction: the VALIANT (VALsartan In Acute myocardial iNfarcTion) Echocardiographic Study. JACC Cardiovasc Imaging 2008;1:582-91.

13. Sarkar S, Srivastava V, Mohanty M. Comparison of efficacy of amlodipine and cilnidipine on left ventricular hypertrophy amongst hypertensive patients. J Hypertens (Los Angel) 2017;6:3.

14. Salvetti M, Paini A, Bertacchini F, et al. Changes in left ventricular geometry during antihypertensive treatment. Pharmacol Res 2018;134:193-9.

15. Costanzo P, Perrone-Filardi P, Petretta M, et al. Calcium channel blockers and cardiovascular outcomes: a metaanalysis of 175,634 patients. J Hypertens 2009;27:1136-51.

16. Lv Y, Zou Z, Chen GM, et al. Amlodipine and angiotensin-converting enzyme inhibitor combination versus amlodipine monotherapy in hypertension: a metaanalysis of randomized controlled trials. Blood Press Monit 2010;15:195-204.

17. Liu F, Qiu M, Zhai SD. Tolerability and effectiveness of (S)-amlodipine compared with racemic amlodipine in hypertension: a systematic review and meta-analysis. Curr Ther Res Clin Exp 2010;71:1-29.

18. Lee SA, Choi HM, Park HJ, et al. Amlodipine and cardiovascular outcomes in hypertensive patients: meta-analysis comparing amlodipine-based versus other antihypertensive therapy. Korean J Intern Med 2014;29:315-24.

19. Wallace BC, Schmid CH, Lau J, et al. Meta-Analyst: software for meta-analysis of binary, continuous and diagnostic data. BMC Med Res Methodol 2009;9:80.

20. Adalet K, Mercanoglu F, Orak E, et al. The effect of amlodipine on the mass and function of the left ventricle in patients with primary hypertension and left ventricular hypertrophy. Curr Ther Res 1995;56:607-11.

21. Beltman FW, Heesen WF, Smit AJ, et al. Effects of amlodipine and lisinopril on left ventricular mass and diastolic function in previously untreated patients with mild to moderate diastolic hypertension. Blood Press 1998;7:109-17.

22. Bilge AK, Atilgan D, Tükek T, et al. Effects of amlodipine and fosinopril on heart rate variability and left ventricular mass in mild-to-moderate essential hypertension. Int J Clin Pract 2005;59:306-10.

23. Fak AS, Okucu M, Tezcan H, et al. The Effects of Amlodipine on Left Ventricular Mass and Diastolic Function in Concentric and Eccentric Left Ventricular Hypertrophy. J Cardiovasc Pharmacol Ther 1996;1:95-100.

24. Fogari R, Mugellini A, Destro M, et al. Losartan and amlodipine on myocardial structure and function: a prospective, randomized, clinical trial. Diabet Med 2012;29:24-31.

25. Gaudio C, Ferri FM, Giovannini M, et al. Comparative effects of irbesartan versus amlodipine on left ventricular mass index in hypertensive patients with left ventricular hypertrophy. J Cardiovasc Pharmacol 2003;42:622-8.

26. Islim IF, Watson RD, Ihenacho $\mathrm{HN}$, et al. Amlodipine: effective for treatment of mild to moderate essential hypertension and left ventricular hypertrophy. Cardiology 2001;96 Suppl 1:10-8.

27. Kloner RA, Sowers JR, DiBona GF, et al. Effect of amlodipine on left ventricular mass in the Amlodipine Cardiovascular Community Trial. J Cardiovasc Pharmacol 1995;26:471-6.

28. Leenen FH, Fourney A. Comparison of the effects of amlodipine and diltiazem on 24-hour blood pressure, plasma catecholamines, and left ventricular mass. Am J Cardiol 1996;78:203-7.

29. Libhaber EN, Libhaber CD, Candy GP, et al. Effect of slow-release indapamide and perindopril compared with amlodipine on 24-hour blood pressure and left ventricular mass in hypertensive patients of African ancestry. Am J Hypertens 2004;17:428-32. 
30. Martina B, Dieterle T, Weinbacher M, et al. Effects of losartan titrated to Losartan/Hydrochlorothiazide and amlodipine on left ventricular mass in patients with mildto-moderate hypertension. A double-blind randomized controlled study. Cardiology 1999;92:110-4.

31. Matsuno Y, Minatoguchi S, Fujiwara H, et al. Effects of candesartan versus amlodipine on home-measured blood pressure, QT dispersion and left ventricular hypertrophy in high-risk hypertensive patients. Blood Press Suppl 2011;1:12-9.

32. Motoki H, Koyama J, Izawa A, et al. Impact of azelnidipine and amlodipine on left ventricular mass and longitudinal function in hypertensive patients with left ventricular hypertrophy. Echocardiography 2014;31:1230-8.

33. Picca M, Bisceglia J, Zocca A, et al. Effects of enalapril and amlodipine on left ventricular hypertrophy and function in essential hypertension. Clin Drug Invest 1997;13:29-35.

34. Rosendorff C, Dubiel R, Xu J, et al. Comparison of olmesartan medoxomil versus amlodipine besylate on regression of ventricular and vascular hypertrophy. Am J Cardiol 2009; 104:359-65.

35. Rutuparna P, Merin D, Abraham S, et al. Assessment of clinical effectiveness of losartan and amlodipine in hypertensive patients with left ventricular hypertrophy. Asian J Pharm Clin Res 2017;10:368-71.

36. Skoularigis J, Strugo V, Weinberg J, et al. Effects of amlodipine on 24-hour ambulatory blood pressure profiles, electrocardiographic monitoring, and left ventricular mass and function in black patients with very severe hypertension. J Clin Pharmacol 1995;35:1052-9.

37. Takami T, Shigematsu M. Effects of calcium channel antagonists on left ventricular hypertrophy and diastolic function in patients with essential hypertension. Clin Exp Hypertens 2003;25:525-35.

38. Terpstra WF, May JF, Smit AJ, et al. Long-term effects of amlodipine and lisinopril on left ventricular mass and diastolic function in elderly, previously untreated hypertensive patients: the ELVERA trial. J Hypertens 2001;19:303-9.

39. Yamamoto K, Ozaki H, Takayasu K, et al. The effect of losartan and amlodipine on left ventricular diastolic function and atherosclerosis in Japanese patients with mildto-moderate hypertension (J-ELAN) study. Hypertens Res 2011;34:325-30.

40. Yasunari K, Maeda K, Watanabe T, et al. Comparative effects of valsartan versus amlodipine on left ventricular mass and reactive oxygen species formation by monocytes in hypertensive patients with left ventricular hypertrophy.
J Am Coll Cardiol 2004;43:2116-23.

41. Yamakado T, Teramura S, Oonishi T, et al. Regression of left ventricular hypertrophy with long-term treatment of nifedipine in systemic hypertension. Clin Cardiol 1994;17:615-8.

42. De Rosa ML, Giordano A, Della Guardia D, et al. Reversal of left ventricular hypertrophy following once daily administration of felodipine for two years to elderly subjects with isolated systolic hypertension. Cardiology 1999;92:39-44.

43. Fogari R, Mugellini A, Zoppi A, et al. Effect of successful hypertension control by manidipine or lisinopril on albuminuria and left ventricular mass in diabetic hypertensive patients with microalbuminuria. Eur J Clin Pharmacol 2005;61:483-90.

44. Neutel JM, Smith DH, Weber MA. Effect of antihypertensive monotherapy and combination therapy on arterial distensibility and left ventricular mass. Am J Hypertens 2004;17:37-42.

45. Ge CJ, Lu SZ, Chen YD, et al. Synergistic effect of amlodipine and atorvastatin on blood pressure, left ventricular remodeling, and C-reactive protein in hypertensive patients with primary hypercholesterolemia. Heart Vessels 2008;23:91-5.

46. Ikeda T, Gomi T, Shibuya Y, et al. Add-on effect of bedtime dosing of the alpha(1)-adrenergic receptor antagonist doxazosin on morning hypertension and left ventricular hypertrophy in patients undergoing long-term amlodipine monotherapy. Hypertens Res 2007;30:1097-105.

47. Mazza A, Townsend DM, Schiavon L, et al. Long-term effect of the perindopril/indapamide/amlodipine singlepill combination on left ventricular hypertrophy in outpatient hypertensive subjects. Biomed Pharmacother 2019;120:109539.

48. Guerra F, Mancinelli L, Angelini L, et al. The association of left ventricular hypertrophy with metabolic syndrome is dependent on body mass index in hypertensive overweight or obese patients. PLoS One 2011;6:e16630.

49. Kurata M, Okura T, Watanabe S, et al. Effects of amlodipine and candesartan on arterial stiffness estimated by cardio-ankle vascular index in patients with essential hypertension: A 24-week study. Curr Ther Res Clin Exp 2008;69:412-22.

50. Fagard RH, Celis H, Thijs L, et al. Regression of left ventricular mass by antihypertensive treatment: a metaanalysis of randomized comparative studies. Hypertension 2009;54:1084-91.

51. Cacciapuoti F. Molecular mechanisms of left ventricular 
hypertrophy (LVH) in systemic hypertension (SH)possible therapeutic perspectives. J Am Soc Hypertens 2011;5:449-55.

52. Sun L, Ji Y, Wang Y, et al. High-sensitive cardiac troponin $\mathrm{T}$ : a biomarker of left-ventricular diastolic dysfunction in hemodialysis patients. J Nephrol 2018;31:967-73.

53. Mishra RK, Li Y, DeFilippi C, et al. Association of cardiac troponin $\mathrm{T}$ with left ventricular structure and function in
CKD. Am J Kidney Dis 2013;61:701-9.

54. Myhre PL, Claggett B, Ballantyne CM, et al. Association Between Circulating Troponin Concentrations, Left Ventricular Systolic and Diastolic Functions, and Incident Heart Failure in Older Adults. JAMA Cardiol 2019;4:997-1006.

(English Language Editor: A. Kassem)

Cite this article as: Gao Y, Zhou D, Yang P. Effect of amlodipine on ventricular hypertrophy in hypertension patients: a systematic review and meta-analysis. Ann Palliat Med 2021;10(10):10768-10778. doi: 10.21037/apm-21-2455 
Supplementary

Table S1 Important characteristics of the included studies

\begin{tabular}{|c|c|c|c|c|c|c|c|c|c|c|c|c|c|c|c|c|c|}
\hline Study & $\mathrm{n}$ & Design & $\begin{array}{c}\text { Follow-up } \\
\text { (months) }\end{array}$ & $\begin{array}{c}\text { HTN } \\
\text { condition }\end{array}$ & Age (years) & Females (\%) & $\mathrm{BMI}\left(\mathrm{kg} / \mathrm{m}^{2}\right)$ & HTN years & SBP & DBP & $\mathrm{HR}$ & LVMI & EF (\%) & FS (\%) & LVPWT (mm) & E/A ratio & LVEDD (mm) \\
\hline Adalet 1995 & 19 & PROSP & 26 & Primary & 52 & 32 & & & $163 \pm 20$ & $102 \pm 5$ & $80 \pm 7$ & $147 \pm 20$ & $68 \pm 9.1$ & & & $1 \pm 0.1$ & \\
\hline Beltman 1998 & 35 & RCT & 10 & Diastolic & $53 \pm 01$ & 49 & $27.2 \pm 4.3$ & & $158 \pm 16$ & $102 \pm 5$ & $69 \pm 9$ & $88 \pm 21$ & & & $9.5 \pm 1.2$ & & $44.9 \pm 4.8$ \\
\hline Bilge 2005 & 14 & RCT & 6 & Essential & $46 \pm 6$ & 43 & $25.9 \pm 3.7$ & & $144 \pm 8$ & $94 \pm 4$ & $82 \pm 5$ & $122 \pm 26$ & & & & & \\
\hline Cerasola 1997 & 11 & PROSP & 6 & Essential & $50 \pm 5$ & 45 & & & $165 \pm 5$ & $105 \pm 3$ & $76 \pm 2$ & $139 \pm 4$ & & $39 \pm 2$ & $13.6 \pm 0.4$ & $1 \pm 0.1$ & $52 \pm 2$ \\
\hline Fak 1996 & 30 & PROSP & 6 & $\begin{array}{l}\text { Mild/ } \\
\text { Moderate }\end{array}$ & $56 \pm 8$ & 27 & & $7 \pm 1.3$ & $164 \pm 14$ & $104 \pm 6$ & $78 \pm 8$ & $160 \pm 30$ & & & $10 \pm 1$ & $1 \pm 0.1$ & $49 \pm 5$ \\
\hline Fogari 2012 & 91 & $\mathrm{RCT}$ & 12 & $\begin{array}{l}\text { Mild/ } \\
\text { Moderate }\end{array}$ & $64 \pm 9$ & 49 & $27.4 \pm 4.3$ & $9.7 \pm 7.2$ & $147 \pm 11$ & $92.1 \pm 7$ & $75 \pm 9$ & $132 \pm 24$ & $64.2 \pm 4.4$ & & $10.3 \pm 1.1$ & $1 \pm 0.2$ & \\
\hline Gaudio 2003 & 30 & $\mathrm{RCT}$ & 6 & Essential & $53.4 \pm 14$ & 43 & & 3.8 & $164 \pm 13$ & $106 \pm 5$ & $74 \pm 7$ & $138 \pm 18$ & & & $11.8 \pm 0.9$ & & $54 \pm 3.3$ \\
\hline Islim 2001 & 33 & PROSP & 5 & Essential & $56.8 \pm 9$ & 42 & & $6.6 \pm 9$ & $173 \pm 15$ & $104 \pm 6$ & $78 \pm 11$ & & $66 \pm 2.5$ & $36 \pm 1.3$ & & & \\
\hline Kloner 1995 & 37 & PROSP & 5 & & & & & & & & & $158 \pm 7$ & & & $11.6 \pm 0.3$ & & $53.1 \pm 1.1$ \\
\hline Leenen 1996 & 17 & $\mathrm{RCT}$ & 6 & Essential & $55 \pm 3$ & 24 & & & $158 \pm 3$ & $102 \pm 2$ & & $107 \pm 5$ & & & & & \\
\hline Libhaber 2004 & 61 & $\mathrm{RCT}$ & 6 & & $54 \pm 10.5$ & 70 & $30.8 \pm 6.5$ & & $153 \pm 15$ & $97 \pm 8$ & & & & & $10 \pm 1.2$ & & $49.1 \pm 5.2$ \\
\hline Martina 1999 & 25 & RCT & 4 & $\begin{array}{l}\text { Mild/ } \\
\text { Moderate }\end{array}$ & $51 \pm 9$ & 12 & $30 \pm 3$ & & $145 \pm 7$ & $100 \pm 5$ & $76 \pm 9$ & $136 \pm 25$ & & & & & \\
\hline Matsuno 2011 & 15 & $\mathrm{RCT}$ & 36 & & $63.8 \pm 9$ & 27 & $24.7 \pm 3.3$ & & $166 \pm 5$ & $93.9 \pm 11$ & & $142 \pm 6$ & & & & & \\
\hline Motoki 2014 & 16 & $\mathrm{RCT}$ & 12 & & $60 \pm 9$ & 25 & $25.3 \pm 4.4$ & & $169 \pm 21$ & $101 \pm 15$ & $72 \pm 13$ & $145 \pm 35$ & & & $12 \pm 2$ & & $47 \pm 7$ \\
\hline Picca 1997 & 32 & $\mathrm{RCT}$ & 18 & Essential & $48 \pm 8$ & 47 & & & $170 \pm 8$ & $102 \pm 6$ & & & $61 \pm 2$ & $34 \pm 2$ & & $1 \pm 0.5$ & $52 \pm 3$ \\
\hline Rosendorff 2009 & 38 & $\mathrm{RCT}$ & 24 & Primary & $64.1 \pm 11$ & 2 & & & $162 \pm 4$ & $90 \pm 3$ & & & & & & & \\
\hline Rutuparana 2017 & 14 & RET & 8 & & $50 \pm 11$ & 50 & & & $149 \pm 15$ & $90 \pm 7$ & & $139 \pm 27$ & & & $12.7 \pm 1.2$ & & $47.6 \pm 3.6$ \\
\hline Sarkar 2017 & 24 & PROSP & 12 & Primary & $57 \pm 3$ & 42 & $23 \pm 3.5$ & & & & & $96 \pm 27$ & $64.4 \pm 4.8$ & $35.4 \pm 4.6$ & & & \\
\hline Skoulurigis 1995 & 21 & PROSP & 3 & Severe & $48 \pm 10$ & & & 5 & $181 \pm 14$ & $119 \pm 6$ & & $140 \pm 50$ & $59 \pm 9$ & $32 \pm 6$ & & & $46.8 \pm 5.2$ \\
\hline Takami 2003 & 15 & $\mathrm{RCT}$ & 6 & Essential & $60.7 \pm 3$ & 0 & $23.1 \pm 0.7$ & & $174 \pm 3$ & $97 \pm 3$ & $67 \pm 3$ & $130 \pm 8$ & & $39.9 \pm 0.8$ & & $1 \pm 0.02$ & $47.1 \pm 1.2$ \\
\hline Terpstra2001 & 81 & $\mathrm{RCT}$ & 24 & & $67 \pm 4$ & 53 & $28.2 \pm 3.4$ & & $175 \pm 15$ & & $92 \pm 8$ & & $109 \pm 20$ & & & & $0.78 \pm 0.18$ \\
\hline Yamamoto 2011 & 28 & $\mathrm{RCT}$ & 18 & Mild/mod & $61 \pm 9$ & 33 & & & $157 \pm 18$ & $96 \pm 14$ & & $143 \pm 47$ & $73 \pm 8$ & & & & \\
\hline Yasunari 2004 & 50 & RCT & 6 & & $64 \pm 12$ & 42 & $24.3 \pm 2.8$ & & $152 \pm 6$ & $92 \pm 6$ & & $161 \pm 39$ & & & & & \\
\hline
\end{tabular}

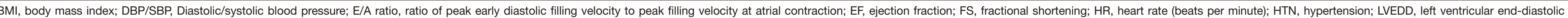
diameter; LVPWT, left ventricular posterior wall thickness; PROSP, prospective; RCT, randomized controlled trial; RET, retrospective; LVMI, left ventricular mass index. 
Tables S2 Quality assessment of the randomized controlled trials

\begin{tabular}{|c|c|c|c|c|c|c|c|}
\hline Study & Other bias & Selective reporting & Incomplete outcome data & Blinding of outcome assessment & Blinding of participants /personnel & Allocation concealment & Random sequence generator \\
\hline Beltman 1998 & L & L & $\mathrm{L}$ & $\mathrm{L}$ & $\mathrm{L}$ & L & $\mathrm{L}$ \\
\hline Bilge 2005 & L & L & $\mathrm{L}$ & $u$ & $u$ & $u$ & $\mathrm{~L}$ \\
\hline Fogari 2012 & $\mathrm{~L}$ & L & $\mathrm{L}$ & $\mathrm{L}$ & $u$ & $\mathrm{H}$ & L \\
\hline Gaudio 2003 & $\mathrm{~L}$ & L & $\mathrm{L}$ & $\mathrm{L}$ & $\mathrm{H}$ & $\mathrm{L}$ & $\mathrm{L}$ \\
\hline Leenen 1996 & $\mathrm{~L}$ & L & $\mathrm{L}$ & u & $\mathrm{H}$ & $\mathrm{L}$ & L \\
\hline Libhaber 2004 & $\mathrm{~L}$ & $\mathrm{~L}$ & $\mathrm{~L}$ & $u$ & $u$ & u & L \\
\hline Martina 1999 & $\mathrm{~L}$ & $\mathrm{~L}$ & $\mathrm{~L}$ & $\mathrm{~L}$ & $\mathrm{~L}$ & $\mathrm{~L}$ & $\mathrm{~L}$ \\
\hline Matsuno 2011 & $\mathrm{~L}$ & L & $\mathrm{L}$ & $\mathrm{L}$ & $\mathrm{H}$ & $\mathrm{H}$ & $\mathrm{L}$ \\
\hline Motoki 2014 & $\mathrm{~L}$ & L & $\mathrm{L}$ & $u$ & $\mathrm{H}$ & u & $\mathrm{L}$ \\
\hline Picca 1997 & $\mathrm{~L}$ & L & $\mathrm{L}$ & u & $\mathrm{L}$ & $\mathrm{u}$ & $\mathrm{L}$ \\
\hline Rosendorff 2009 & $\mathrm{~L}$ & $\mathrm{H}$ & $\mathrm{L}$ & $\mathrm{L}$ & $\mathrm{L}$ & $\mathrm{L}$ & $\mathrm{L}$ \\
\hline Takami 2003 & $\mathrm{~L}$ & $\mathrm{~L}$ & $\mathrm{~L}$ & $u$ & $u$ & $\mathrm{u}$ & $\mathrm{L}$ \\
\hline Terpstra 2001 & L & $\mathrm{L}$ & L & L & L & L & L \\
\hline Yamamoto 2011 & L & L & L & L & $\mathrm{H}$ & H & L \\
\hline Yasunari 2004 & $\mathrm{~L}$ & L & L & $\mathrm{L}$ & $\mathrm{L}$ & L & L \\
\hline
\end{tabular}

$\mathrm{H}$, high risk; L, low risk; U, unclear risk.

Table S3 Newcastle-Ottawa scale for assessment of quality of observational cohort studies (each asterisk represents if individual criterion within the subsection was fulfilled)

\begin{tabular}{|c|c|c|c|c|c|c|c|c|}
\hline Study & $\begin{array}{l}\text { Representativeness of } \\
\text { exposed cohort? }\end{array}$ & $\begin{array}{l}\text { Selection of non-exposed } \\
\text { cohort? }\end{array}$ & Ascertainment of exposure & $\begin{array}{l}\text { Demonstration that outcome of } \\
\text { interest was not present at start }\end{array}$ & $\begin{array}{l}\text { Comparability of cohorts on } \\
\text { basis of design or analysis }\end{array}$ & Assessment of outcome & $\begin{array}{l}\text { Was follow-up long enough for } \\
\text { outcomes to occur }\end{array}$ & $\begin{array}{l}\text { Adequacy of follow up of } \\
\text { cohort }\end{array}$ \\
\hline Adalet 1995 & $\star$ & & $\star$ & $\star$ & & $\star$ & $\star$ & $\star$ \\
\hline Cerasola 1997 & $\star$ & & $\star$ & $\star$ & & $\star$ & $\star$ & $\star$ \\
\hline Fak 1996 & $\star$ & & $\star$ & $\star$ & $\star$ & $\star$ & $\star$ & $\star$ \\
\hline Islim 2001 & $\star$ & & $\star$ & $\star$ & & $\star$ & $\star$ & \\
\hline Kloner 1995 & $\star$ & & $\star$ & $\star$ & & $\star$ & & $\star$ \\
\hline Rutuparna 2017 & $\star$ & & $\star$ & $\star$ & & $\star$ & $\star$ & \\
\hline Sarkar 2017 & $\star$ & & $\star$ & $\star$ & $\star$ & $\star$ & $\star$ & $\star$ \\
\hline Skoularigis 1995 & $\star$ & $\star$ & $\star$ & $\star$ & & $\star$ & & $\star$ \\
\hline
\end{tabular}



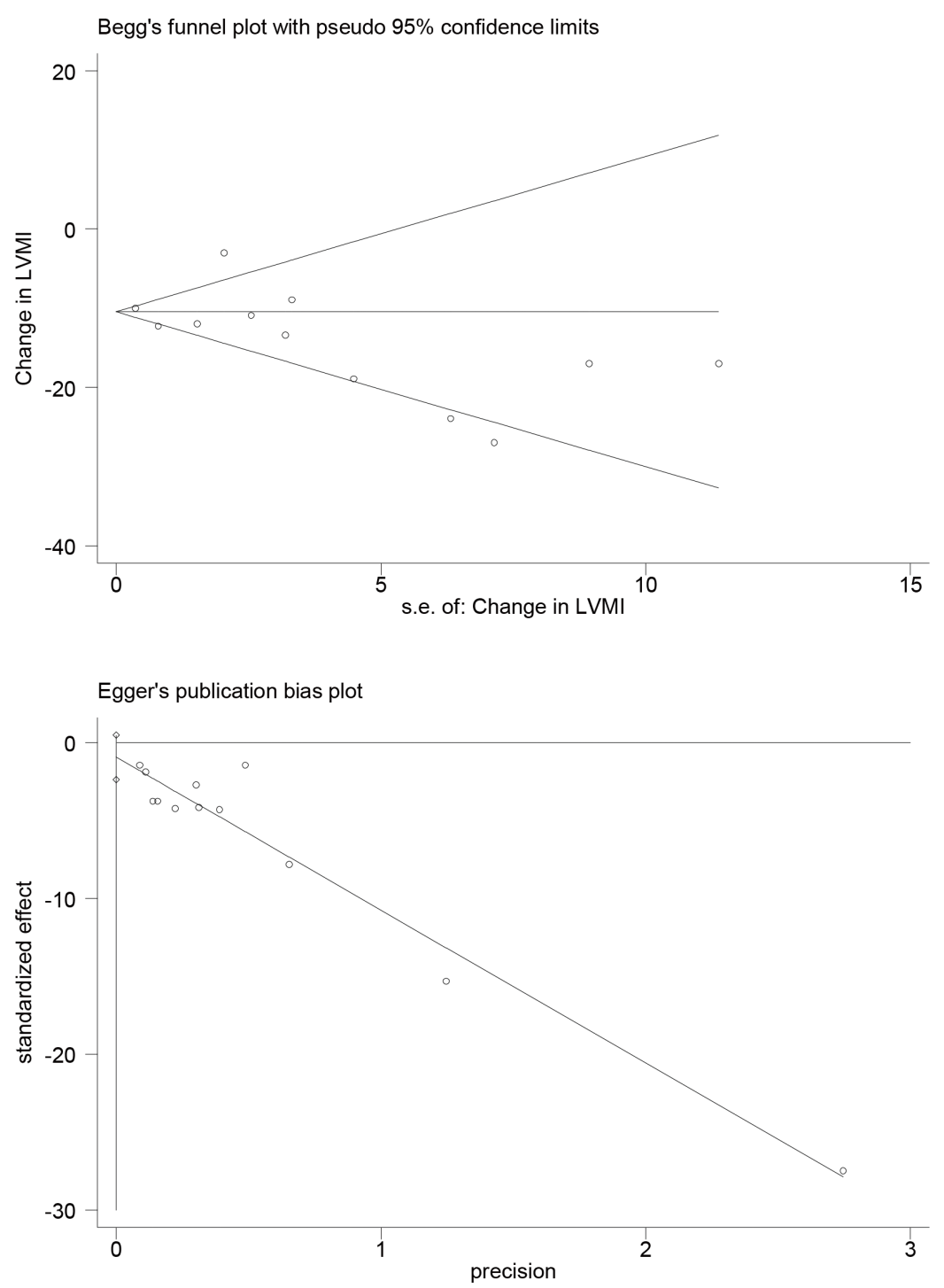

Figure S1 Graphical outcomes of the publication bias assessment tests. LVMI, left ventricular mass index. 

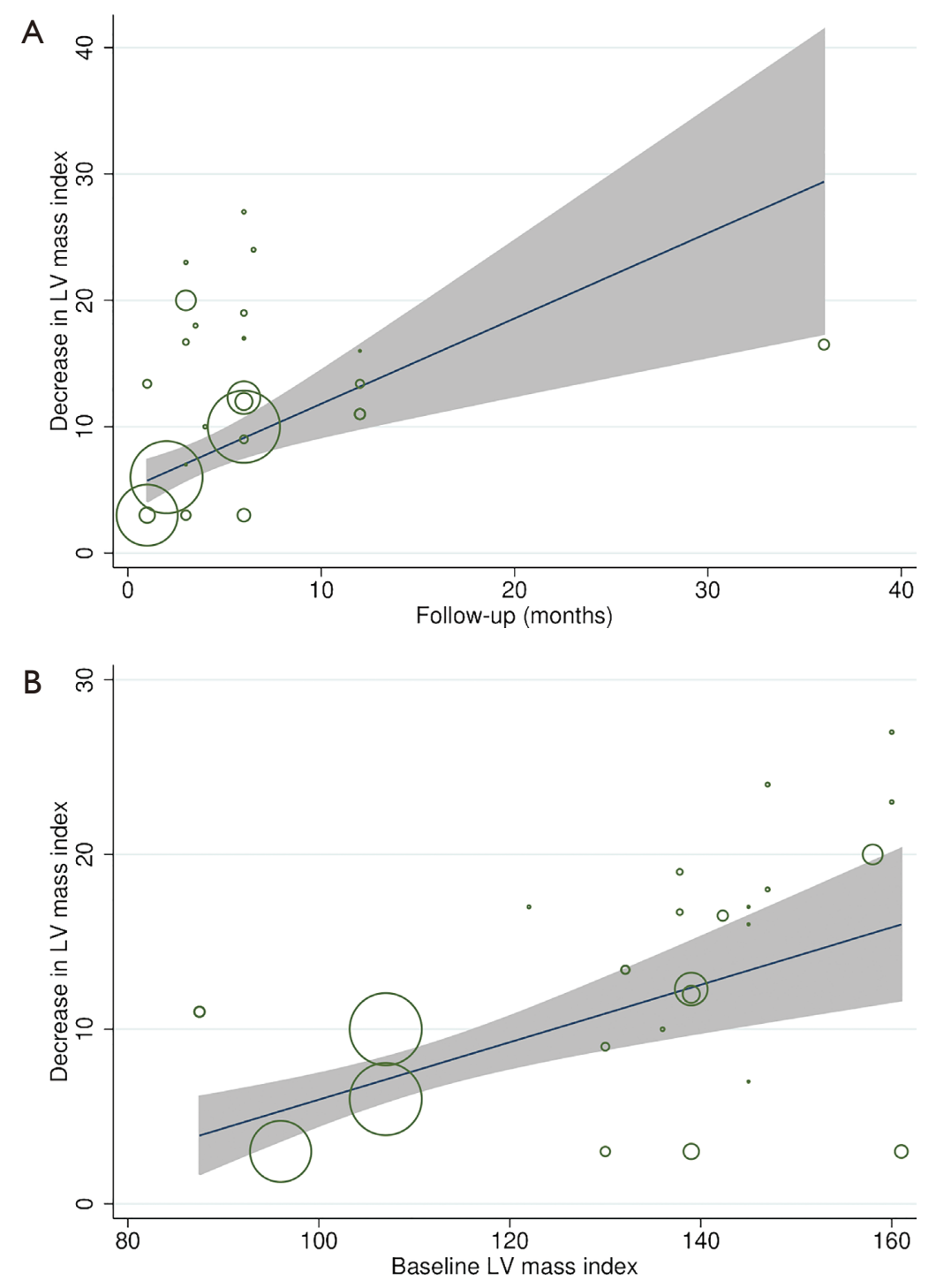

Figure S2 Meta-regression scatterplots showing the relationship between the decrease in Left ventricular (LV) mass index after amlodipine treatment and (A) follow-up duration and (B) baseline LV mass index. 


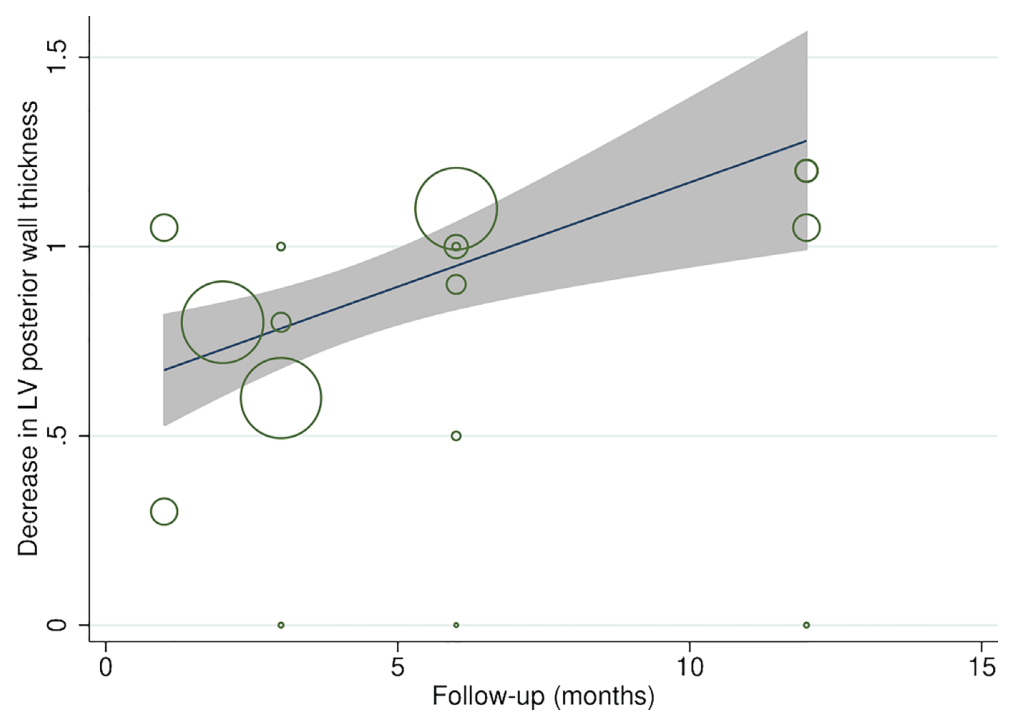

Figure S3 Meta-regression scatterplots showing the relationship between the decrease in Left ventricular (LV) posterior wall thickness after amlodipine treatment and the follow-up duration. 


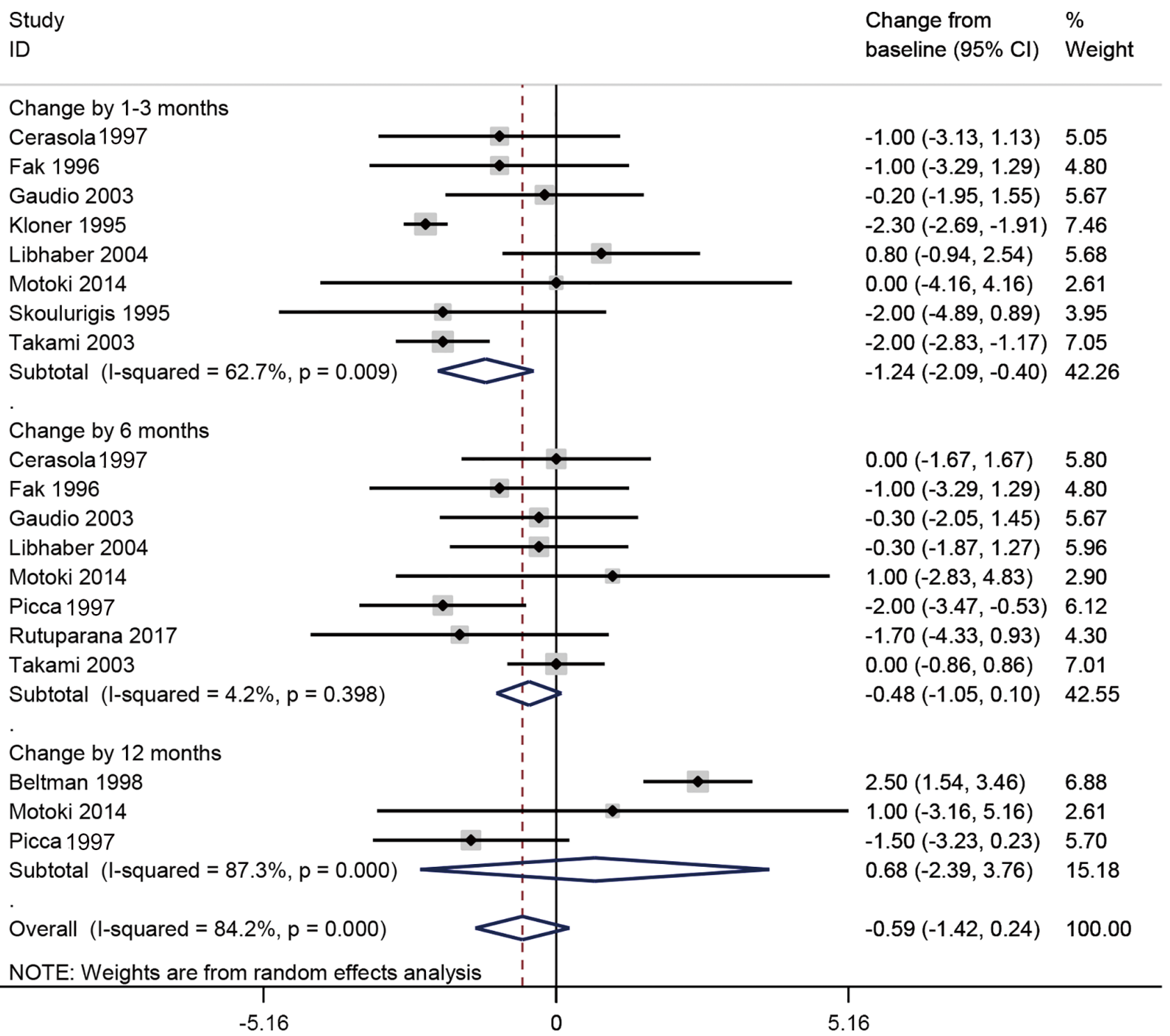

Figure S4 A forest graph showing the outcomes of the meta-analysis of changes from baseline in Left ventricular (LV) end-diastolic diameter. 


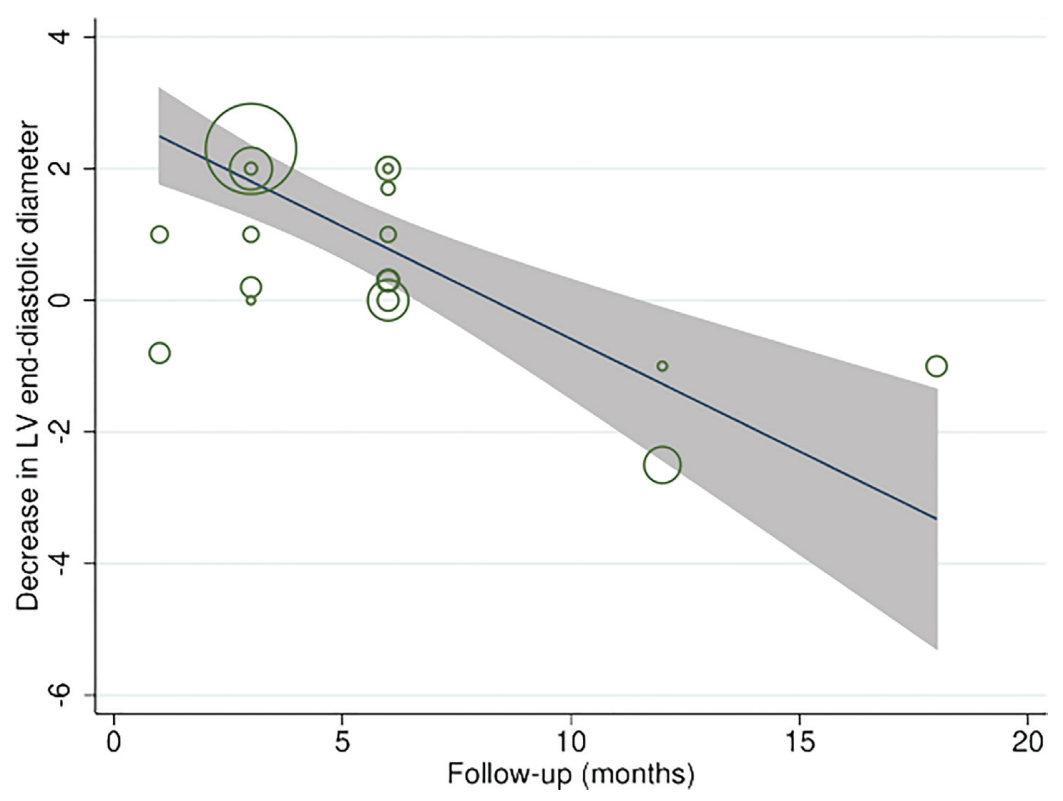

Figure S5 Meta-regression scatterplots showing the relationship between the decrease in Left ventricular (LV) end-diastolic diameter and the follow-up duration. 